\title{
The Efficacy of High-Volume Evacuators and Extraoral Vacuum Aspirators in Reducing Aerosol and Droplet in Ultrasonic Scaling Procedures during the COVID-19 Pandemic
}

\author{
Trijani Suwandi $^{10}$ Vidya Nursolihati ${ }^{10}$ Mikha Sundjojo ${ }^{10}$ Armelia Sari Widyarman ${ }^{20}$ \\ ${ }^{1}$ Department of Periodontics, Faculty of Dentistry, Trisakti University, \\ Grogol Jakarta Barat, Indonesia \\ 2 Department of Microbiology, Faculty of Dentistry, Trisakti \\ University, Grogol Jakarta Barat, Indonesia \\ Address for correspondence Armelia Sari Widyarman, Department of \\ Microbiology, Faculty of Dentistry, Trisakti University, Jln. Kyai Tapa \\ 260, Grogol Jakarta Barat 11440, Indonesia \\ (e-mail: armeliasari@trisakti.ac.id).
}

Eur J Dent 2022;16:803-808.

\begin{abstract}
Keywords

- aerosol

- droplet

- extraoral vacuum aspirators

- high-volume evacuators

- ultrasonic scaling
\end{abstract}

Objective SARS-CoV-2 can be carried by aerosols and droplets produced during dental procedures, particularly by the use of high-speed handpieces, air-water syringes, and ultrasonic scalers. High-volume evacuators (HVEs) and extraoral vacuum aspirators (EOVAs) reduce such particles. However, there is limited data on their efficacy. This study aimed to determine the efficacy of HVE and EOVA in reducing aerosols and droplets during ultrasonic scaling procedures.

Materials and Methods Three ultrasonic scaling simulations were conducted on mannequins: 1. saliva ejector (SE) was used alone (control); 2. SE was used in combination with HVE; and 3. SE was used in combination with HVE and EOVA. Paper filters were placed on the operator's and assistant's face shields and bodies, and the contamination of aerosols and droplets was measured by counting blue spots on the paper filters.

Statistical Analysis All data were analyzed for normality using the KolmogorovSmirnov test. The differences between each method were analyzed using a two-way ANOVA, followed by a posthoc test. The differences were considered statistically significant when $p<0.05$.

Result Using HVE and EOVA reduced aerosols and droplets better than using SE alone or SE and HVE: the posthoc test for contamination revealed a significant difference $(p<0.01)$. The assistant was subjected to greater contamination than the operator during all three ultrasonic scaling procedures.

Conclusion The usage of HVE and EOVA significantly reduced aerosols and droplets compared with using SE solely. Using these techniques together could prevent the transmission of airborne disease during dental cleanings, especially COVID-19. Further studies of aerosol-reducing devices are still needed to ensure the safety of dental workers and patients. published online January 11,2022
DOI https://doi.org/ 10.1055/s-0041-1739448. ISSN 1305-7456.
(C) 2022. The Author(s).

This is an open access article published by Thieme under the terms of the Creative Commons Attribution License, permitting unrestricted use, distribution, and reproduction so long as the original work is properly cited. (https://creativecommons.org/licenses/by/4.0/)

Thieme Medical and Scientific Publishers Pvt. Ltd., A-12, 2nd Floor, Sector 2, Noida-201301 UP, India 


\section{Introduction}

Coronavirus disease 2019 (COVID-19) is an infectious respiratory disease caused by severe acute respiratory syndrome Coronavirus 2 (SARS-CoV-2). ${ }^{1}$ It has been declared as a pandemic by the World Health Organization (WHO) and millions of cases continue to be reported around the world. Until now, several mutations and variants of SARS-CoV-2 have emerged throughout the world, namely, B.1.1.7 (alpha), B.1.351 (beta), P1 (gamma), and B.1.617.2 (delta). ${ }^{2}$ Recent studies suggested that delta variant spreads faster, causes more infections, is 40 to $60 \%$ more contagious than the alpha variant, and may be the most transmissible variant. 2,3

SARS-CoV-2 is mainly transmitted between people through contact and respiratory droplets routes. ${ }^{4,5}$ Respiratory droplets, which are $>5$ to $10 \mu \mathrm{m}$ in diameter, are released when a person coughs, sneezes, or talks, while droplets $\leq 5 \mu \mathrm{m}$ in diameter are referred to as droplet nuclei or aerosols, which can remain in the air over long distances and time. ${ }^{4}$ An additional category of larger droplets, more than $50 \mu \mathrm{m}$ in diameter, is described as splatter in some studies. 6,7 Even though COVID-19 transmission through contact or droplets inhalation is considered as the main route of transmission, another potential route of transmission can occur via airborne through inhalation of aerosol and droplet exhaled by an infected person. ${ }^{7,8}$

Dental procedures that generate aerosols ("aerosolgenerating procedures") are considered as high-risk mode of SARS-CoV-2 airborne transmission. ${ }^{4,9}$ Several reports indicate that ultrasonic scaling procedures are one of the largest major sources of aerosols and droplets ${ }^{10}$ that are mainly contaminated with bacteria and viruses. ${ }^{11}$ Therefore, safety and infection control procedures are very important to minimize the risk of transmission, one of which is by reducing the number of aerosols and droplets. ${ }^{10}$ The currently used aerosol-reducing devices are low-volume evacuators such as saliva ejectors (SEs), high-volume evacuators (HVEs), and extraoral vacuum aspirators (EOVAs). 5, 10,12,13

The SEs usually used by dentists have small suction tips that are not large enough to remove a large number of aerosols. ${ }^{10}$ The Centers for Disease Control and Prevention (CDC) recommend aerosols contamination control during dental treatment using techniques and devices such as high-velocity air evacuation and HVEs and EOVAs. It could reduce aerosols up to 93 to $96 \%$ in dental clinics. ${ }^{10,12,13}$ However, the research methods and data discussing on the effectiveness of using these devices to reduce aerosols and droplets during ultrasonic scaling are scarce. Moreover, no study in the literature has compared the efficacy of HVE and EOVA in reducing aerosols when used alone or together. This is the first study that compares the effectiveness of SE alone, SE and HVE, as well as SE, HVE and EOVA in reducing aerosols and droplets in dental procedure (ultrasonic scaling) both on operators and dental assistants using disclosing solutions and paper filters to capture aerosol and droplet dispersion.

\section{Materials and Methods}

The method used in this study is a modification from a pilot study by Veena et al. ${ }^{14}$ Ultrasonic scaling simulation was performed using a piezoelectric ultrasonic scaler (EMS, Swiss) on a mannequin with jaw simulator (Kavo Dental, Germany) and placed in supine position on dental unit (Clesta II, Belmont, Japan). The dental unit and ultrasonic scaler water lines was filled with a mixture of $10 \mathrm{mg}$ disclosing solution (GC Tri Plaque ID Gel, Japan) and $1000 \mathrm{~mL}$ aquadest. Paper filter with grids (Whatman ME25/21ST, Sigma-Aldrich, St. Louis, Missouri) made from mixed cellulose ester membranes (cellulose acetate and cellulose nitrate) was used to capture aerosol and droplet, because it has uniform microporous structure, which gives high-flow rates for greater adsorption. The paper filter with grid lines provide excellent contrast for easier particle detection to assist in manual counting procedures. These paper filters were placed with adhesive tapes on the operator's and assistant's face shields (which covered the forehead, both cheeks, and chin) and on several parts of the bodies: chest, right shoulder and left shoulder, and three paper filters on both arms with $15 \mathrm{~cm}$ distance on each arm. Each paper filter was marked with code, according to their position, as shown in - Fig. 1.

\section{Ultrasonic Scaling Simulation}

The operator performed the scaling simulation at 11 o'clock position, while the assistant held the SE or HVE positioned at 1 o'clock position in manner of mannequin head

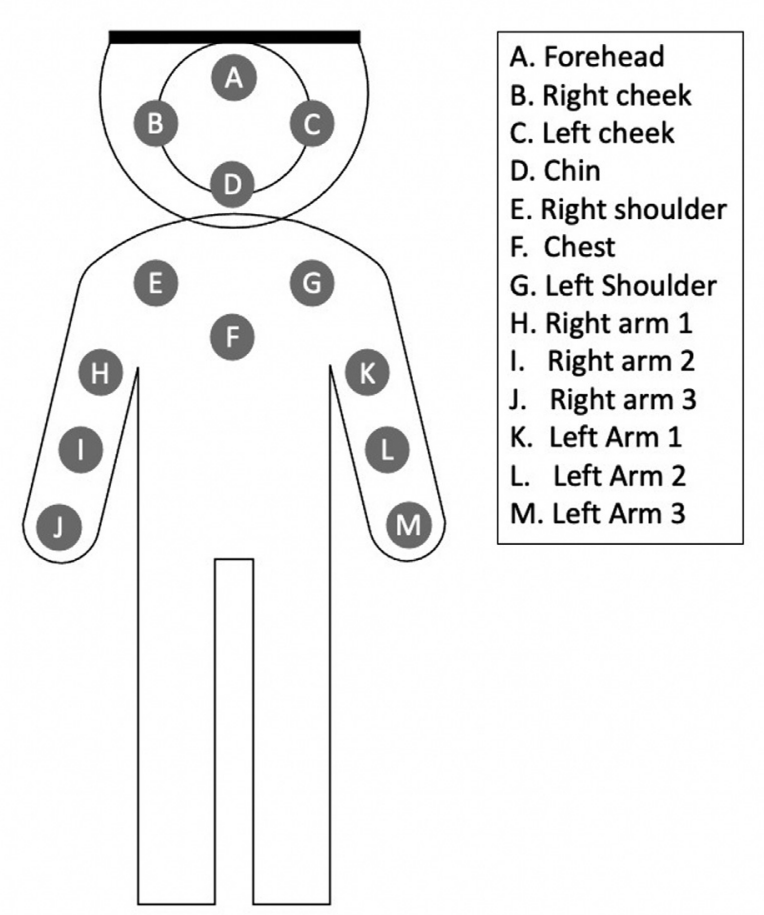

Fig. 1 Schematic distribution of the paper filters on the body ( $A=$ forehead; $B=$ right cheek; $C=$ left cheek, $D=$ chin; $E=$ right shoulder; $\mathrm{F}=$ chest, $\mathrm{G}=$ left shoulder; $\mathrm{H}=$ right arm $1 ; \mathrm{I}=$ right $\operatorname{arm} 2$; $\mathrm{J}=$ right $\operatorname{arm} 2 ; \mathrm{K}=$ left $\operatorname{arm} 1 ; \mathrm{L}=$ left arm 2; $\mathrm{M}=$ left arm 3). 
considered as 12 o'clock position. Each simulation was performed for 15 minutes. Based on the aerosol-reducing devices used in the procedures, the scaling simulations were divided into three groups: group 1, the control group, using SE alone; group 2 using SE and HVE; and group 3 using SE, HVE, and EOVA (Coxo, Guangdong, China) together where the suction hood distanced $15 \mathrm{~cm}$ from mannequin mouth. The scaling procedure was repeated 20 times for each group.

\section{Measurement of Aerosol and Droplet Contamination}

The extent aerosols and droplets contamination on the paper filters was measured in $\mathrm{mm}^{2}$ units. Square on paper filter was categorized as contaminated if there is at least a blue spot inside the square. Measurement was done by manually counting total contaminated squares on paper filters multiplied by $9.61 \mathrm{~mm}^{2}$ (square area of each square on paper filter). The total contaminated area on each paper filter was measured by counting the number of contaminated squares. The mean contaminant area is the mean contaminated area on paper filters from 20 repeated scaling simulations of each group (-Fig. 2).

\section{Statistical Analysis}

All data was collected and analyzed for normality using the Kolmogorov-Smirnov test. The differences between each method were analyzed using a two-way ANOVA, followed by a posthoc test. The differences were considered statistically significant when $p<0.05$ (SPSS statistic version 20, IBM, USA).
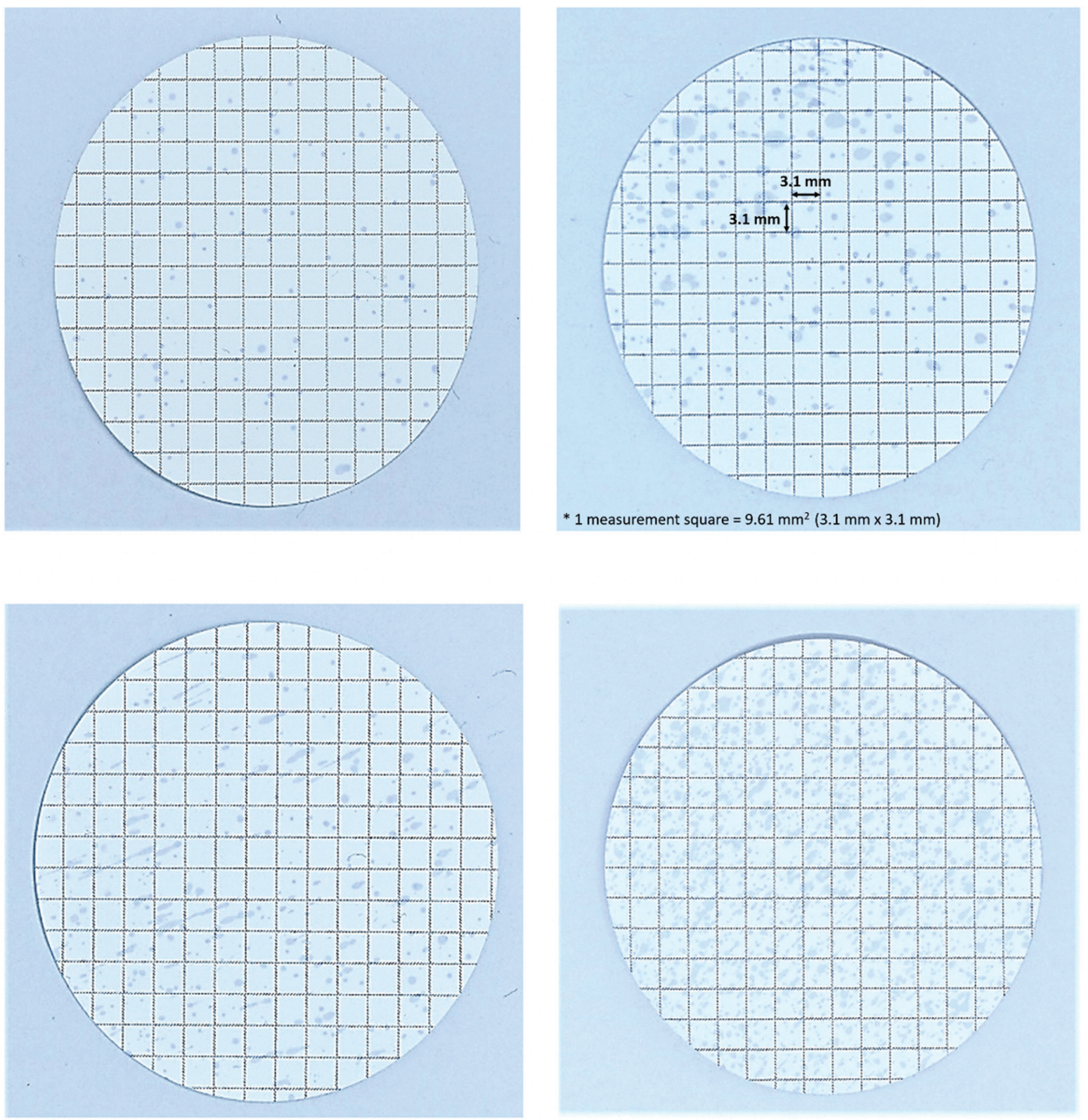

Fig. 2 Contamination visible on paper filters. 


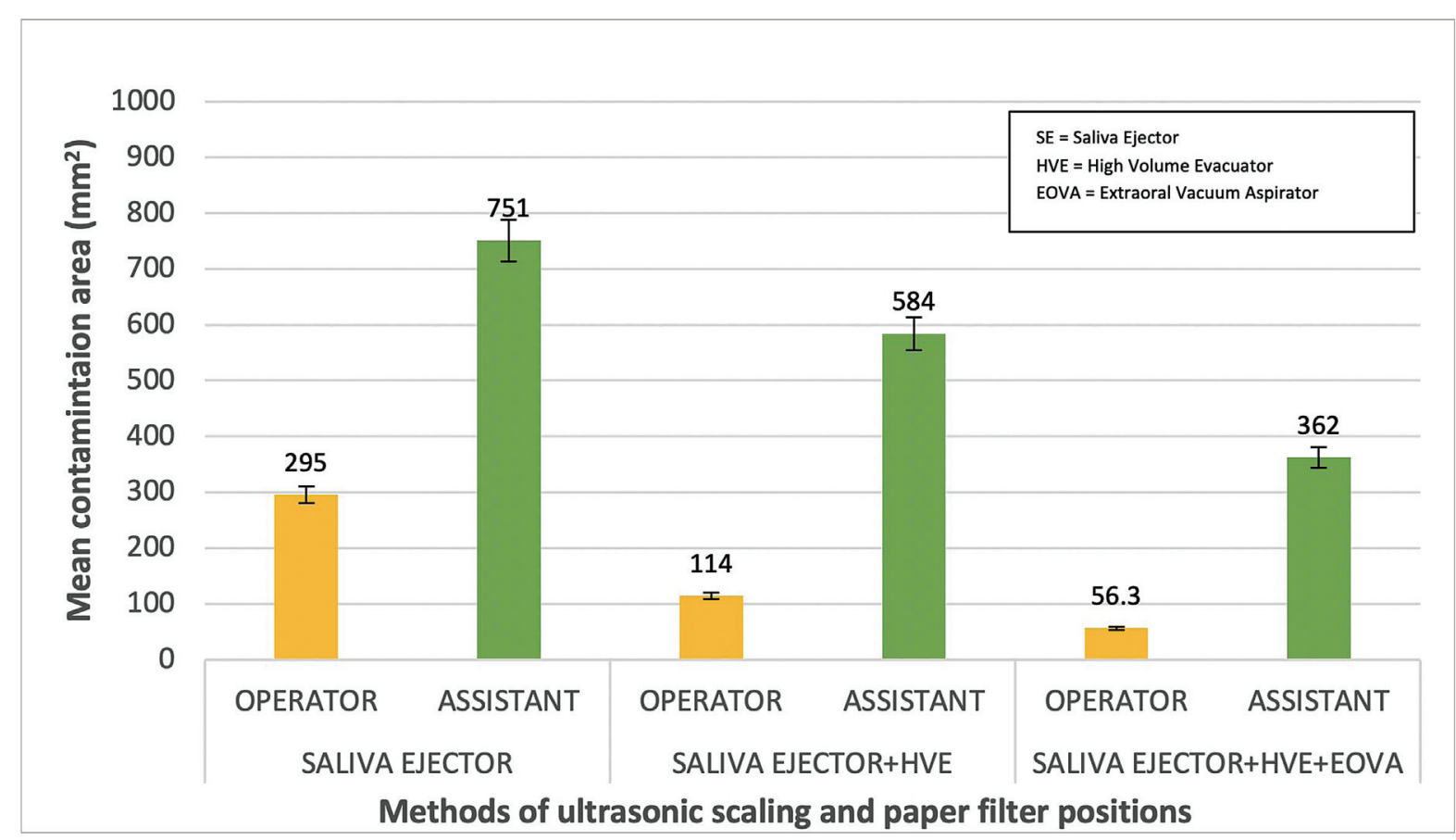

Fig. 3 Means of the contamination area according to scaling groups and paper filter positions. EOVA, extraoral vacuum aspirator; HVE, highvolume evacuator; SE, saliva ejector.

\section{Results}

The mean contamination areas found on the operator and assistant following the three methods of ultrasonic scaling are shown in - Fig. 3. Of the three methods, ultrasonic scaling using SE, HVE, and EOVA (group 3) was most effective at reducing aerosols.

Statistical analysis using a two-way ANOVA test showed that the ultrasonic scaling procedure using SE, HVE, and EOVA significantly reduced aerosols and droplets $(p<0.01)$ compared with using SE alone and SE and HVE (-Table 1).
The results of the posthoc test for contamination areas on the operator and assistant showed a significant difference $(p<0.01)$, as the assistant was subjected to more contamination than the operator during the ultrasonic scaling methods used in all three procedures (-Table 2 ).

\section{Discussion}

This study shows that using HVE and EOVA in ultrasonic scaling procedures reduces aerosols and droplets contamination on paper filters around the working zone (-Fig. 3 ).

Table 1 Statistical analysis of contamination area from each method used in ultrasonic scaling procedures using a two-way ANOVA test

\begin{tabular}{|c|c|c|c|c|c|c|}
\hline \multicolumn{7}{|c|}{ Comparison } \\
\hline Method & Method & Mean difference & SE & df & $\mathbf{t}$ & p-Value \\
\hline \multirow[t]{2}{*}{ SE } & $\mathrm{SE}+\mathrm{HVE}$ & 179 & 7.42 & 1456 & 24.1 & $<0.001$ \\
\hline & $\mathrm{SE}+\mathrm{HVE}+\mathrm{EOVA}$ & 314 & 7.33 & 1456 & 42.8 & $<0.001$ \\
\hline $\mathrm{SE}+\mathrm{HVE}$ & $\mathrm{SE}+\mathrm{HVE}+\mathrm{EOVA}$ & 135 & 7.42 & 1456 & 18.2 & $<0.001$ \\
\hline
\end{tabular}

Abbreviations: EOVA, extraoral vacuum aspirator; HVE, high-volume evacuator; SE, saliva ejector.

Table 2 Results of the posthoc test for contamination present on the operator and assistant following the ultrasonic scaling procedures

\begin{tabular}{|c|c|c|c|c|c|c|}
\hline \multicolumn{7}{|c|}{ Comparison } \\
\hline Position & Position & Mean difference & $\mathrm{SE}$ & df & $\mathrm{t}$ & P-Value \\
\hline Operator & Assistant & -408 & 6.03 & 1456 & -67.6 & $<0.001$ \\
\hline
\end{tabular}


Previous studies have shown that SE was not effective enough to reduce aerosols production in ultrasonic scaling procedures. It only reduced water from the floor of the mouth but continued to spread aerosols throughout the working area, including the dental operator's and assistant's personal workspace. $^{14,15}$

SARS-CoV-2 can transmit and infect people through aerosol transmission, ${ }^{16}$ thus having HVE at constant operation during dental operation can significantly reduce aerosol production up to 90 to $98 \%{ }^{17}$ This study presented significantly lower mean contamination area when using HVE combined with SE. These findings ultimately lead to the importance and the high-necessity of having HVE in dental settings, especially during this pandemic era when dental practices are needed. Moreover, to further reduce possible aerosol contamination use EOVA with HVE. Our study also showed a further mean reduction in the contamination area after using EOVA with HVE. A previous study conducted by Shahdad et al particularly documented the efficacy of splatter contamination reduction in a dental aerosol-generating procedure by using EOVA. ${ }^{18}$

The utilization of EOVA was uncommon in prepandemic situation, but its efficacy in reducing aerosols has been assessed. ${ }^{19}$ Since the pandemic, every measure to potentially reduce aerosol transmission in dental practices is sought out, with hopes that dental practitioners can still continue their work during the pandemic. ${ }^{20}$ With the result from this study, combination usage of HVE with EOVA becomes prominent for dental settings.

The two-way ANOVA test revealed less droplets were captured on the paper filters when HVE and EOVA were used ( - Table 1). HVE requires a dental assistant to hold and direct the tip while maintaining a 6 to $15 \mathrm{~mm}$ distance from the working zone. ${ }^{5,17}$ EOVA is more effective when located $14 \mathrm{~mm}$ from the working zone rather than $18 \mathrm{~mm} .{ }^{21}$ However, studies on the effectiveness of HVE and EOVA are still limited and further studies on the design, power, and recommended instructions for using these devices are still needed.

The extent and contamination of droplets and aerosols on person (operator, patient, and assistant) also need to be identified to manage the risk of disease transmission. Although droplets contamination on person during ultrasonic scaling procedure have been reported in many papers, only few papers considered at contamination of the assistant, of which were found on assistant's head and chest. ${ }^{6}$ Our study result shows more contamination in the assistant's body compared with the operator's body (-Table 2 ). This variance between papers possibly results from different methodologies used in each paper.

Aerosols produced by ultrasonic scaling can remain in the air for 30 minutes. $^{14}$ Studies also suggest that SARSCoV-2 can persist and remain alive in aerosols for hours, ${ }^{22}$ thus it is recommended that dental workers do not immediately remove their personal protective equipment (PPE) after work. ${ }^{14}$ Reducing the risk of airborne contamination from ultrasonic scaling procedures could be achieved by using HVE, but using SE alone is not recommended. ${ }^{23}$ Alternatively, minimizing the risk of infection from airborne particles in dental treatment facilities could be achieved by several means, aside from using the combination of SE, HVE, and EOVA, such as; using filter in the ventilation systems (for example, high-efficiency particulate air [HEPA] filters), ${ }^{24}$ using ultraviolet (UV) light for sterilization prior to dental service, ${ }^{25}$ and/or applying negative pressure during dental procedure. By applying negative pressure, airborne time of aerosols becomes limited as the aerosols were drawn downward, thus reducing aerosol contaminants further. ${ }^{26}$ Furthermore, the risk of microbial transmission could be minimized by decreasing microbial bioload with preprocedural mouth rinse and dental unit water line decontamination. 27

This study results show that dental workers can benefit from the utilization of HVE and EOVA during ultrasonic scaling, as it reduced significant amount of aerosols and droplets around patient's mouth, thereby decreasing the risk of cross-contamination of pathogens. The advantages of the method used in the study are it is a simple and low-cost method, easy to set-up, and also reproducible. The disadvantages are the range areas of aerosol and droplet capture are limited. Our study still has several limitations. It only counts aerosols and droplets contamination on the operator's and assistant's bodies, and there is no description on the pathogens composition that serve as the source of infection. We suggest future study on aerosol contamination in larger areas with microbiological evaluation.

\section{Conclusion}

This study findings showed that using HVE and EOVA with SE reduced the aerosols and droplets production during ultrasonic scaling procedures significantly compared with using SE solely. These devices could be a beneficial addition to dentistry practices, in order to reduce the risk of disease transmission, especially COVID-19. The results also indicate that dental assistants are at greater risk for being contaminated by aerosols and droplets. Therefore, the use of complete PPE is crucial. Further studies of aerosol-reducing devices are still needed to ensure the safety of dental workers and patients.

Conflict of Interest

None declared.

\section{References}

1 Ge ZY, Yang LM, Xia JJ, Fu XH, Zhang YZ. Possible aerosol transmission of COVID-19 and special precautions in dentistry. J Zhejiang Univ Sci B 2020;21(05):361-368

2 Raman R, Patel KJ, Ranjan K. COVID-19: unmasking emerging SARS-CoV-2 variants, vaccines and therapeutic strategies. Biomolecules 2021;11(07):993. Doi: 10.3390/biom11070993

3 Variant D. What We Know About the Science. Accessed August 29, 2021 at: https://www.cdc.gov/coronavirus/2019-ncov/variants/ delta-variant.html

4 Transmission of SARS-CoV-2: implications for infection prevention precautions. Accessed: August 29, 2021 at: https://www. who.int/news-room/commentaries/detail/transmission-of-sarscov-2-implications-for-infection-prevention-precautions 
5 Farook FF, Mohamed Nuzaim MN, Taha Ababneh K, Alshammari A, Alkadi L. COVID-19 pandemic: oral health challenges and recommendations. Eur J Dent 2020;14(S 01):S165-S170

6 Johnson IG, Jones RJ, Gallagher JE, et al. Dental periodontal procedures: a systematic review of contamination (splatter, droplets and aerosol) in relation to COVID-19. BDJ Open 2021;7(01):15

7 Ram K, Thakur RC, Singh DK, et al. Why airborne transmission hasn't been conclusive in case of COVID-19? An atmospheric science perspective. Sci Total Environ 2021;773:145525

8 Bazant MZ, Bush JWM. A guideline to limit indoor airborne transmission of COVID-19. Proc Natl Acad Sci U S A 2021;118 (17):e2018995118

9 Lloro V, Giovannoni ML, Luaces VL, Manzanares MC. Perioral aerosol sequestration suction device effectively reduces biological crosscontamination in dental procedures. Eur J Dent 2021;15(02):340-346

10 Harrel SK, Barnes JB, Rivera-Hidalgo F. Aerosol and splatter contamination from the operative site during ultrasonic scaling. J Am Dent Assoc 1998;129(09):1241-1249

11 Peng X, Xu X, Li Y, Cheng L, Zhou X, Ren B. Transmission routes of 2019$\mathrm{nCoV}$ and controls in dental practice. Int J Oral Sci 2020;12(01):9

12 Centers for Disease Control and Prevention. Morbidity and mortality weekly report (MMWR): Recommended infection-control practices for dentistry. Accessed October 19, 2020 at: https:// www.cdc.gov/mmwr/PDF/rr/rr4208.pdf

13 Motegi N, Ikegami Y, Chiba M, Asano Y. The effect of extra-oral suction on aerosol reduction. Dent Outlook 2010;115(06):1-18

14 Veena HR, Mahantesha S, Joseph PA, Patil SR, Patil SH. Dissemination of aerosol and splatter during ultrasonic scaling: a pilot study. J Infect Public Health 2015;8(03):260-265

15 Harrel SK, Molinari J. Aerosols and splatter in dentistry: a brief review of the literature and infection control implications. J Am Dent Assoc 2004;135(04):429-437

16 Lotfi M, Hamblin MR, Rezaei N. COVID-19: Transmission, prevention, and potential therapeutic opportunities. Clin Chim Acta 2020;508:254-266
17 Rajeev K, Kuthiala P, Ahmad FN, et al. Review article aerosol suction device: mandatory armamentarium in dentistry post lock down. J Adv Med Dent Sci Res. 2020;8(04):81-83

18 Shahdad S, Patel T, Hindocha A, et al. The efficacy of an extraoral scavenging device on reduction of splatter contamination during dental aerosol generating procedures: an exploratory study [published correction appears in Br Dent J. 2020 Oct 13]. Br Dent J 2020:1-10. Doi: 10.1038/s41415-020-2112-7

19 Teanpaisan R, Taeporamaysamai M, Rattanachone P, Poldoung N, Srisintorn $S$. The usefulness of the modified extra-oral vacuum aspirator (EOVA) from household vacuum cleaner in reducing bacteria in dental aerosols. Int Dent J 2001;51(06):413-416

20 Chavis SE, Hines SE, Dyalram D, Wilken NC, Dalby RN. Can extraoral suction units minimize droplet spatter during a simulated dental procedure? J Am Dent Assoc 2021;152(02):157-165

21 Ou Q Placucci RG, Danielson J, et al. Characterization and mitigation of aerosols and spatters from ultrasonic scalers. J Am Dent Assoc 2021;152(12):981-990

22 Allison JR, Currie CC, Edwards DC, et al. Evaluating aerosol and splatter following dental procedures: Addressing new challenges for oral health care and rehabilitation.J Oral Rehabil 2021;48(01):61-72

23 Matys J, Grzech-Leśniak K. Dental aerosol as a hazard risk for dental workers. Materials (Basel) 2020;13(22):5109

24 Zhao B, An N, Chen C. Using an air purifier as a supplementary protective measure in dental clinics during the coronavirus disease 2019 (COVID-19) pandemic. Infect Control Hosp Epidemiol 2021;42(04):493

25 Cumbo E, Gallina G, Messina P, Scardina GA. Alternative methods of sterilization in dental practices against COVID-19. Int J Environ Res Public Health 2020;17(16):5736

26 Al-Benna S. Negative pressure rooms and COVID-19. J Perioper Pract 2021;31(1-2):18-23

27 Kumar PS, Geisinger ML, Avila-Ortiz G. Methods to mitigate infection spread from aerosol-generating dental procedures. J Periodontol 2021;92(06):784-792 